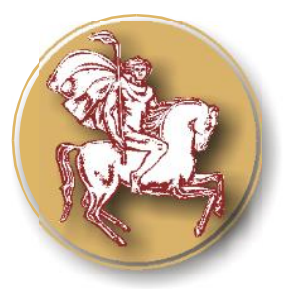

Trakia Journal of Sciences, No 3, pp 280-283, 2021

Copyright (C) 2021 Trakia University Available online at:

http://www.uni-sz.bg

ISSN 1313-3551 (online)

doi:10.15547/tjs.2021.03.013

Case Report

\title{
INTRAPERITONELA MULTINODULAR SPLENOSIS - AN INCIDENTAL EMERGENT LAPAROTOMY FINDING: A RARE CASE REPORT.
}

\author{
Iv. Novakov ${ }^{1 *}$, M. Gulinac ${ }^{2}$ \\ ${ }^{1}$ Department of Special Surgery, Medical Faculty, Medical University, Plovdiv, Bulgaria \\ ${ }^{2}$ Department of Pathology, Medical Faculty, Medical University, Plovdiv, Bulgaria
}

\begin{abstract}
Splenosis is a rare benign condition that arises from the heterotopic autotransplantation of splenic tissue following iatrogenic or accidental splenic trauma. The aim of this publication is to present a rare case of multinodular intraperitoneal splenosis as an incidental finding at the time of emergent laparotomy, with a gap of more than 51 years after previous abdominal trauma.
\end{abstract}

Key words: splenosis, trauma, laparotomy

\section{INTRODUCTION}

Splenosis is a rare benign condition that arises from the heterotopic autotransplantation of splenic tissue following iatrogenic or accidental splenic trauma. It usually occurs within the abdominal cavity, involving the visceral and parietal peritoneum. In general, patients with abdominal splenosis are most commonly asymptomatic and in the majority of them this entity is diagnosed accidentally (1-3).

In the literature, the interval between splenic trauma and diagnosis of splenosis widely varies: from several months to 42 years $(1,4)$.

The aim of this publication is to present a rare case of multinodular intraperitoneal splenosis as an incidental finding at the time of emergent laparotomy, with a gap of more than 51 years after previous abdominal trauma.

\section{CASE PRESENTATION}

A 90-year-old woman was presented to our emergency department with a complaint of sudden onset of severe epigastric pain. Abdominal physical examination revealed scar through the middle line of epigastrium and umbilical region, the rigidity of the abdominal musculature with rebound tenderness.

\footnotetext{
*Correspondence to: Ivan Petkov NOVAKOV, Peshersko shosse 66; Plovdiv 4000 ; Bulgaria Phone: +359887575487, E-mail address: inovakov2003@yahoo.com
}

Lateral decubitus abdominal radiograph detected pneumoperitoneum - as a small collection of free air under the anterior abdominal wall.

The woman's past surgical history was notable in that she had undergone a laparotomy and splenectomy for thoraco-abdominal trauma 51 years earlier.

Her blood test was unremarkable (HGB $134,0 / \mathrm{L}$; erythrocyte count: $4,63 \times 10^{12} / \mathrm{L}$; white cell count: $8,34 \times 10^{9} / \mathrm{L}$; platelet count: $\left.238,0 \times 10^{9} / \mathrm{L}\right)$.

Perforation of hollow abdominal organ was diagnosed and the woman was taken immediately into surgery. Median laparotomy was performed. Exploration of the peritoneal cavity established perforated ulcer on the lesser curvature of the duodenal bulb with fibrotic edges of the ulcer. Ulcer was excised and pyloroduodenal defect was closured by Juddpyloroplasty.

During the laparotomy (just after entering the peritoneal cavity) multiple solid masses were found onto the great omentum, mesentery of the large and small bowel (Figure 1). These multiple nodules were oval and rounded, well demarcated, bluish, with size from some $\mathrm{mm}$ to $3 \mathrm{~cm}$ in diameter (Figure 2). Macroscopically, they were detected as intraperitoneal splenic implants. 


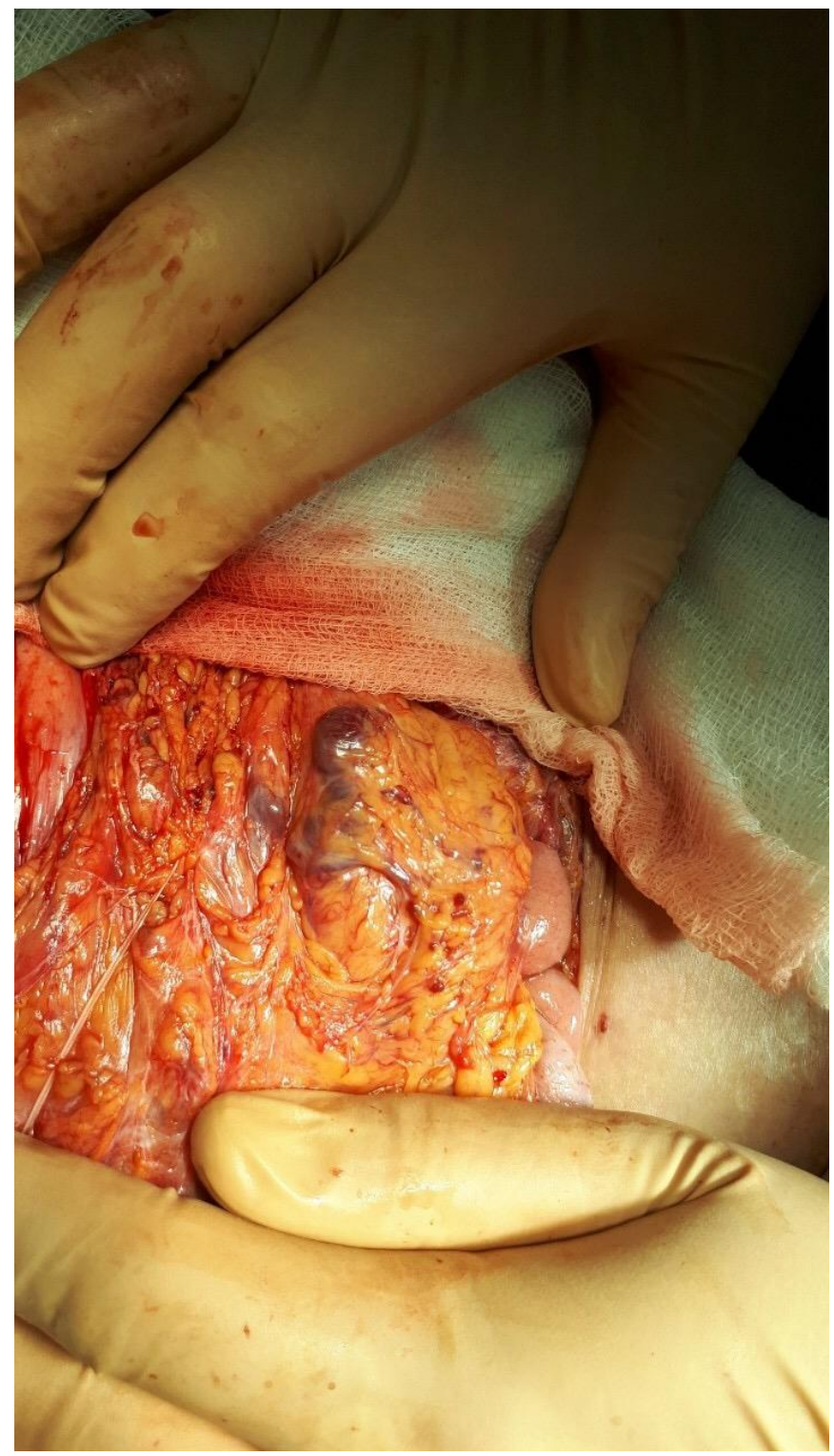

Figure 1. Operative finding: intrapertioneal splenic nodules.

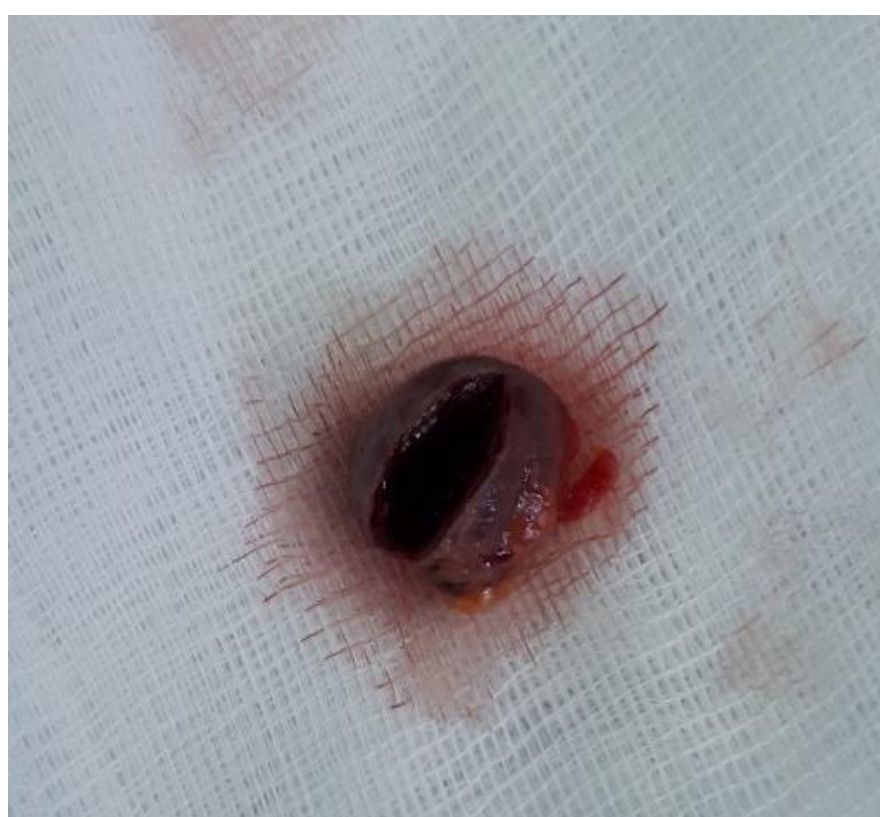

Figure 2. Gross pathology presentation of splenic nodule removed from the great omentum. 
Excisional biopsy of two of the nodules (from the great omentum) was performed and the specimens were sent for hystological examination. It revealed ectopic trabecular splenic tissue with hemosiderin deposition in the red pulp (Figure 3A, B, C).

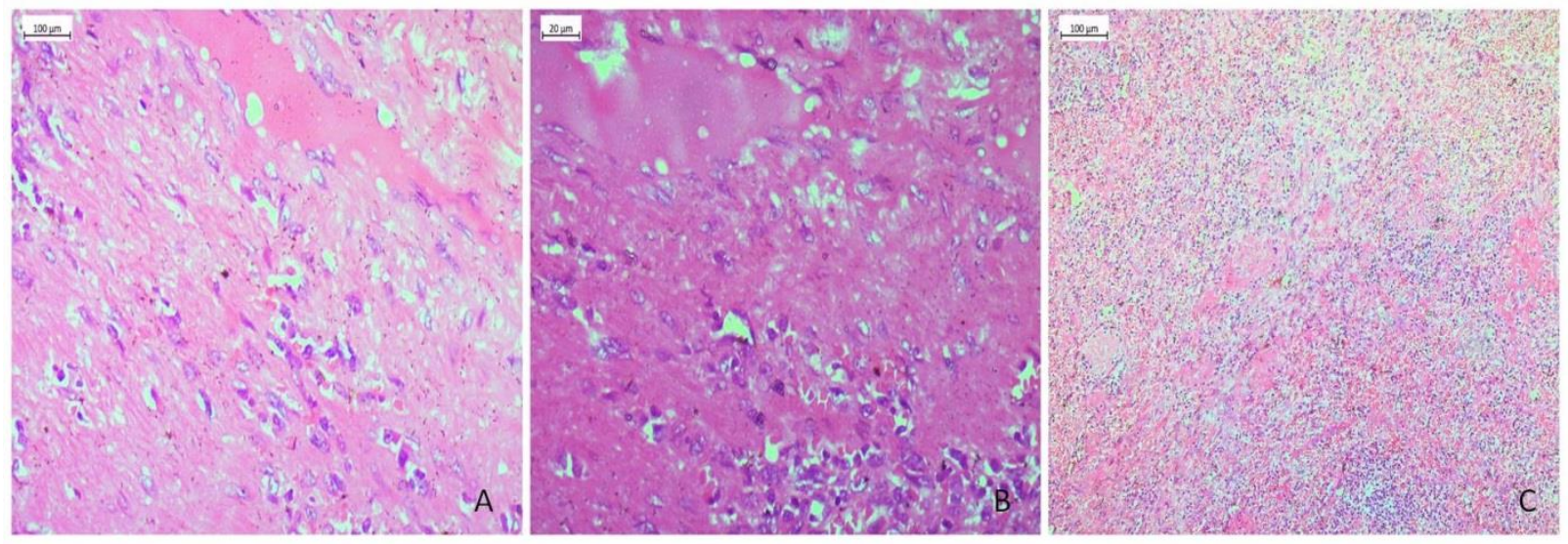

Figure 3. Histological presentations of ectopic splenic nodule (hematoxylin\&eosin staining). 3A\&3B: trabecular structure of the red pulp (x100); 3C: hemosiderin deposition in the red pulp, venous sinusoids of red pulp are filling with erythrocytes (x20).

Postoperatively, the woman was admitted to intensive care unit with death on the $6^{\text {th }}$ day of her hospitalization.

\section{DISCUSSION}

Splenosis is defined as autotransplantation of splenic tissue; most commonly result of abdominal trauma with subsequent splenectomy. The true incidence of splenosis remains unknown. Generally, this pathological entity is usually asymptomatic and the splenic nodules are found accidentally during unrelated diagnostic procedures imaging or surgery $(1,4-$ $6)$. The interval between the splenic injury and the diagnosis of splenosis, reported in the literature, varies from several months to 42 years $(1,4)$. The present case is interesting with the longest reported interval -51 years, in the oldest reported patient -90 years.

Two mechanisms of autotransplantation of splenic tissue are considered $(1,7,8)$. The first one is post-traumatic spilling and seeding of the splenic pulp in the surrounding structures with birth to splenic nodules over time. Another mechanism of splenosis is the hematogenous spread of splenic pulp. The abdominal cavity is the most common site of splenosis, involving visceral and parietal peritoneum, as a result of splenic pulp spilling.

The number of the reported intraperitoneal splenic nodules varies from single to numerous (more than 400) / $(1,9,10)$. With the current case, we present a form of intraperitoneal splenosis with an excessive number of splenic autotransplants, without having the purpose to determine their exact number. Our case confirms the usual operative finding of intraperitoneal splenosis: oval and rounded nodules, less than $3 \mathrm{~cm}$ in diameter, welldemarcated and most often bluish. This gross pathology presentation, helping by medical history of the previous splenectomy, is essential for making an operative diagnosis "abdominal splenosis".

The definitive diagnosis of splenosis should be made by histological examination. The structure of ectopic splenic nodules may vary from the normal spleen architecture to various stages of distorted architecture (11-13). We established the structure of intraperitoneal nodules as most of the authors describe: white and red pulp, with lack of trabecular structures and hemosiderin deposition in the red pulp.

Surgical removal of intraperitoneal splenosis is considered unnecessary $(1,14,15)$. The implanted splenic tissue offers some degree of protection against bacterial infection lowering the frequency of post-splenectomy sepsis. In the presenting case, we followed the current opinion- if the intraperitoneal splenosis is an incidental operative finding in an asymptomatic patient, complete surgical removal of splenic nodules is not indicated.

\section{CONCLUSION}

In conclusion, we present a case of intraperitoneal splenosis, incidentally diagnosed at the time of emergent abdominal surgery. The presenting case is interesting with the extremely long interval between 
establishing the splenosis and previous splenic injury in very old patients.

\section{REFERENCES}

1. Ksiadzyna D, Peña AS. Abdominal splenosis. Rev Esp Enferm Dig, 103:421426, 2011.

2. Sánchez-Paniagua I, González B, Roberto GF. Splenosis: Non-invasive diagnosis of a great mimicker. Esp Enferm Dig, 108:40-41, 2016.

3. Depypere L, Goethals M, Janssen A et al. Traumatic rupture of splenic tissue 13 years after splenectomy. A case report. Acta Chir Belg, 109:523-6, 2009.

4. Ksiadzyna D. Abdominal splenosis with clinical presentation of metastatic neoplastic disease. Gastroenterol Review, 5:356-359, 2010.

5. Fremont RD, Rice TW. Splenosis: a review. South Med J, 100(6):589-593, 2007.

6. Imbriaco M, Camera L, Manciuria A, Salvatore M. A case of multiple intraabdominal splenosis with computed tomography and magnetic resonance imaging correlative findings. World $J$ Gastroenterol, 14(9):1453-1455, 2008.

7. Kwok CM, Chen YT, Lin HT, Su CH, Liu YS, Chiu YC. Portal vein entrance of splenic erythrocytic progenitor cells and local hypoxia of liver, two events cause intrahepatic splenosis. Med Hypotheses, 67:1330-1332, 2006.

8. El-Kheira Al, Abdelnourb M, Boutrosc JG.
NOVAKOVIV., et al.

Simultaneous small bowel and colon obstruction due to splenosis. A case report and review of literature. Intern Jour of Surg Case Reports, 58:63-66, 2019.

9. Al-Ahmadi M, Brundage S, Brody F, Jacobs L, Sackier JM. Splenosis of the mesoappendix: case report and review of the literature. J R Coll Surg Edinb, 43:200-202, 1998.

10.Ananthan K, Gibran TY, Mayur K. Intrahepatic and intra-abdominal splenosis: A case report and review of literature. World J Hepatol, 11(12):773-779, 2019.

11.Jahanshir A, Bahreini M, Mirfazaelian H et al. Intraabdominal Splenosis. International Journal of Surgical Pathology, 23(2) 123124, 2015.

12. Matsubayashi $\mathrm{H}$, Bando E, Kagawa $\mathrm{H}$ et al. A Multinodular Mass of Abdominal Splenosis: Case Report of Uncommon Images of a Rare Disease. Diagnostics, 99:111-117, 2019.

13. Yildiz AE, Ariyurek MO, Karcaaltincaba M. Splenic anomalies of shape, size, and location: Pictorial essay. Sci. World J, doi:10.1155 /2013/321810, 2013.

14.Zitzer P, Pansky M, Maymon R et al. Pelvic splenosis mimicking endometriosis, causing low abdominal mass and pain. Hum Reprod, 13:1683-1685, 1998.

15.Bresciani C, Ferreira NR, Perez RO. Splenosis mimicking gastric gist: case report and literature review. Arq Bras Cir Dig, 24(2):183-185, 2011. 